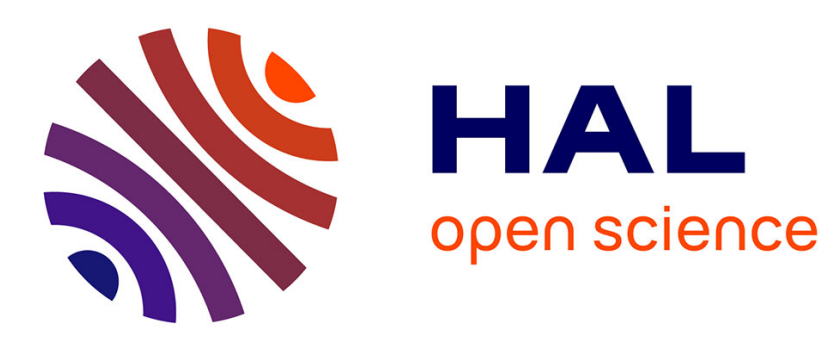

\title{
A Radiative Technique for Measuring the Thermal Properties of Road and Urban Materials
}

Sophie Parison, Martin Hendel, Arnaud Grados, Kristine Jurski, Laurent

Royon

\section{- To cite this version:}

Sophie Parison, Martin Hendel, Arnaud Grados, Kristine Jurski, Laurent Royon. A Radiative Technique for Measuring the Thermal Properties of Road and Urban Materials. Road Materials and Pavement Design, In press. hal-02272929

\section{HAL Id: hal-02272929 \\ https://hal.science/hal-02272929}

Submitted on 4 Sep 2019

HAL is a multi-disciplinary open access archive for the deposit and dissemination of scientific research documents, whether they are published or not. The documents may come from teaching and research institutions in France or abroad, or from public or private research centers.
L'archive ouverte pluridisciplinaire HAL, est destinée au dépôt et à la diffusion de documents scientifiques de niveau recherche, publiés ou non, émanant des établissements d'enseignement et de recherche français ou étrangers, des laboratoires publics ou privés. 


\title{
A Radiative Technique for Measuring the Thermal Properties of Road and Urban Materials
}

\author{
Sophie PARISON ${ }^{\mathrm{a}, \mathrm{b}}$, Martin HENDEL ${ }^{\mathrm{a}, \mathrm{c}}$, Arnaud GRADOS ${ }^{\mathrm{d}}$, Kristine JURSKI ${ }^{\mathrm{d}}$, Laurent ROYON ${ }^{\mathrm{a}}$ \\ a Univ Paris Diderot, Sorbonne Paris Cité, LIED, UMR 8236, CNRS, F-75013, Paris, France. (corresponding \\ author) sophie.parison@univ-paris-diderot.fr \\ b Paris City Hall, Water and Sanitation \& Road and Transportation Departments, F-75014, Paris, France. \\ c Université Paris-Est, ESIEE Paris, département SEN, Noisy-le-Grand, F-93162, France. \\ d Univ Paris Diderot, Sorbonne Paris Cité, MSC, UMR 7057, CNRS, F-75013, Paris, France.
}

\begin{abstract}
The impact of urban construction materials, including pavement structures, on the urban climate depends on their thermal properties. However, their determination with standard methods is made difficult by the presence of large heterogeneities and their surface roughness. We propose a radiation-based method to overcome these difficulties and characterize their apparent thermal properties (conductivity, specific heat, etc.). The approach is compared with results obtained by using the hot-disk and the hot-plate methods and shows good agreement for smooth and homogenous material samples. The method is found to be useful for characterizing the thermal properties of materials with varying heterogeneity and surface roughness.
\end{abstract}

Keywords: apparent thermal property, heterogeneous materials, rough materials, urban material

\section{Nomenclature}

\section{Symbols:}

$a \quad$ thermal diffusivity, $\mathrm{m}^{2} \cdot \mathrm{s}^{-1}$

$c_{p} \quad$ specific heat capacity, $\mathrm{J} \cdot \mathrm{kg}^{-1} \cdot \mathrm{K}^{-1}$

D sample diameter

$e \quad$ element thickness, $\mathrm{m}$

E thermal effusivity, $\mathrm{J} \cdot \mathrm{m}^{-2} \cdot \mathrm{K}^{-1} \cdot \mathrm{s}^{-1 / 2}$

FAA fine-aggregate asphalt

$k$ thermal conductivity, $\mathrm{W} \cdot \mathrm{m}^{-1} \cdot \mathrm{K}^{-1}$

PCC Portland cement concrete

$s$ slope, ${ }^{\circ} \mathrm{C} . \mathrm{s}^{-1}$

$t$ time, $\mathrm{s}$

\author{
T temperature, ${ }^{\circ} \mathrm{C}$ \\ Greek letters: \\ $\delta T \quad$ temperature interval, ${ }^{\circ} \mathrm{C}$ \\ $\phi \quad$ absorbed heat flux density, W. $\mathrm{m}^{-2}$ \\ $\rho \quad$ density, kg.m ${ }^{-3}$
}

$\begin{array}{ll}\text { Indexes / Exponents: } \\ 0 \quad \text { initial } \\ i & \text { insulating } \\ * & \text { reduced }\end{array}$

\section{Introduction}

Pavements and roads, which cover large areas in cities, contribute to the Urban Heat Island (UHI) effect. During the day, pavements absorb and store significant amounts of solar radiation and then release it back during the night to the surrounding environment. This phenomenon generates serious problems in terms of air quality [1], high urban energy consumption [2], and public health problems [3], which explain why recent research efforts have been devoted to developing adaptation/mitigation strategies.

In order to understand the UHI effect with respect to pavements, many studies have focused on their thermal properties: albedo, thermal conductivity, heat capacity, dry density and emissivity [4-6]. Many of them show that surfaces with high albedo exhibit lower maximum daily surface temperature whereas materials with high emissivity have lower surface temperature during the night time [7]. Nevertheless, 
these studies still present inaccuracies due essentially to a lack of knowledge of the other thermal properties of a pavement system. This is mainly related to the complex structure of public roads which are composed of several different material layers such as Portland cement concrete (PCC), asphalt, mortar, granite, gravel, etc. These materials often include aggregates of various sizes reaching up to several centimeters. Such heterogeneities and surface roughness render standard thermal characterization methods impractical for these materials. Nevertheless, a detailed knowledge of the thermo-physical properties of the urban fabric materials would allow a better understanding of their thermal behaviour (heating processes, heat storage and release etc.) and their contribution to the UHI phenomenon. This information would be useful to decision makers for urban planning in order to reduce pedestrians thermal stress during heat waves.

Among the different methods existing in the lab, contact transient methods using plane or linear heating elements (hot-wire [8-9], hot-plate [10-11], hot-disk [12-13], divided-bar [14] or three-layer [15] methods) allow direct identification of the thermal conductivity and diffusivity for a material assumed to be homogeneous and isotropic [16] but their implementation remains constraining for the case of a heterogeneous material [17-18]. Indeed, the sensor/heating element must be large enough in regard to the typical size of the heterogeneities for them to be taken into account. In addition, ensuring good thermal contact between the heating element and sample remains difficult for rough surfaces.

A radiative heating source can be used to overcome the issue of poor heating element contact with the sample surface. One such approach is the flash method, which provides an estimate of sample thermal diffusivity [19-21]. To obtain a good estimation of diffusivity, convective exchanges with the sample must be characterized, and additional corrections may be applied to take into account the duration of the flashimpulse [22].

The present research proposes to apply a semi-steady-state laboratory method based on a radiative heat source [23], similar to the flash method, which provides a direct assessment of apparent thermal conductivity $(k)$ and of apparent volumetric heat capacity $\left(\varrho . c_{p}\right)$. The main strength of the method is the simplicity in the calculation of the thermal properties based on two temperature measurements. The method also proceeds during a short period of experiment and presents the advantage of doing without the need for contact between the heating element (radiative source) and the sample.

We apply this method to a set of six heterogeneous urban materials: fine-aggregate asphalt (FAA), granite, mortar, stabilized sand, asphalt concrete and PCC. Those materials were selected among the most commonly used in the parisian road fabric: FAA is traditionally used for sidewalk, granite for sidewalk borders or slabs, stabilized sand is commonly found in parks or green-spaces walking paths, asphalt concrete is used on traffic road while PCC and mortar are used as structural sub-layers.

Results are compared with those obtained with two other techniques for smooth and homogeneous samples: the hot-disk and the hot-plate methods [24].

\section{Methodology}

\subsection{Radiation-based characterization method}

A diagram of the experimental set-up is illustrated in Figure 1. To ensure a unidirectional thermal transfer, a cylindrical sample ten times wider than it is thick is placed in a polyurethane insulation ring with a bottom insulation layer, leaving only the top of the sample exposed. An infrared lamp is used to heat the top of the sample with a constant radiative heat flux. To normalize the radiative properties of different materials, the top of each sample is coated with matte black paint (absorptivity of 0.95). The sample is initially at thermal equilibrium. 


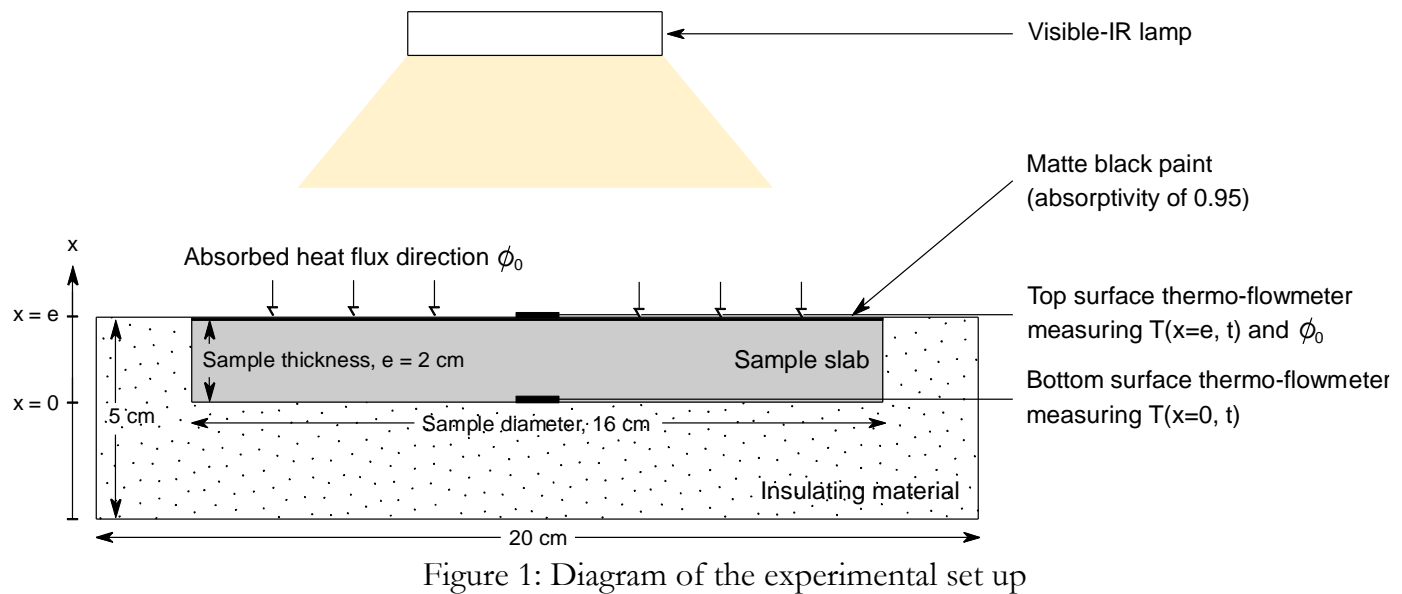

A few minutes before $t=0$, the lamp is switched on to allow it to heat up with the sample shielded from its radiation. At $t=0$, the sample is exposed to the radiation source, thus submitting the sample to a step of uniform constant heat flux density.

Over the duration of the experiment, temperature and heat flux are measured on the top face with a combined T-type thermocouple and fluxmeter sensor (Captec, France). On the bottom face of the sample, a second T-type thermocouple is placed at the interface between the sample and the insulating material. The typical sensitivity of the heat flux sensor given by the manufacturer is equal to $1.25 \mu \mathrm{V} /\left(\mathrm{W} . \mathrm{m}^{-2}\right)$ and the accuracy of the copper-constantin thermocouple is $\pm 0.3^{\circ} \mathrm{C}$. Data was acquired every second.

To ensure identical radiative conditions, the top sensor is also painted with the same matte black paint as the sample surface. This sensor measures absorbed radiation net of convective transfers with the ambient air, i.e. the net heat flux density $\phi_{0}$ absorbed by the sample.

\subsection{Mathematical model of heat transfer}

The transient heat transfer problem is considered geometrically and thermally symmetric along the vertical direction ( $x$-axis). Heat transfer equation along the $x$-axis inside the sample and on its surface is expressed by the following equation:

$\rho c_{p} \frac{\partial T}{\partial t}=k\left(\frac{\partial^{2} T}{\partial x^{2}}\right)$

where $k, c_{p}$ and $\varrho$ are the thermal conductivity, the specific heat capacity and the density of the sample, respectively.

Consider $\phi_{0}$ the radiation heat density absorbed by the pavement sample and $T_{0}$ the initial temperature of the system. Initial and boundary conditions are explicitly given in equations (2), (3) and (4), respectively.

$T(x, t=0)=T_{0}$

$\frac{\partial T}{\partial x}_{\mid x=0}=0$

$-k \frac{\partial T}{\partial x}_{\mid x=e}=\phi_{0}$

Considering that the sample thickness is approximately one tenth of its diameter $(e<<D)$ and that its periphery is thermally insulated, heat diffusion along the longitudinal axis can be neglected. The heat transfer is thus rendered unidirectional along the $\mathrm{x}$-axis over the duration of the experiment. Also 
considering that the thermal properties of the sample are constant, the resolution of the heat equation thus gives the following analytical expression:

$T(x, t)=T_{0}+\frac{\phi_{0} t}{\rho c_{p} e}+\frac{\phi_{0} e}{k}\left[\frac{3 x^{2}-e^{2}}{6 e^{2}}-\frac{2}{\pi^{2}} \sum_{n=1}^{\infty} \frac{(-1)^{n}}{n^{2}} \exp \left(-\frac{k n^{2} \pi^{2} t}{e^{2}}\right) \cos \left(\frac{n \pi x}{e}\right)\right]$

An example of temperature profiles on the upper $(x=e)$ and lower $(x=0)$ surfaces of the sample as a function of time are reported in Figure 2. It can be observed that the temperature profiles increase strongly at first and then show a linear progression when a local quasi-steady state condition is reached.

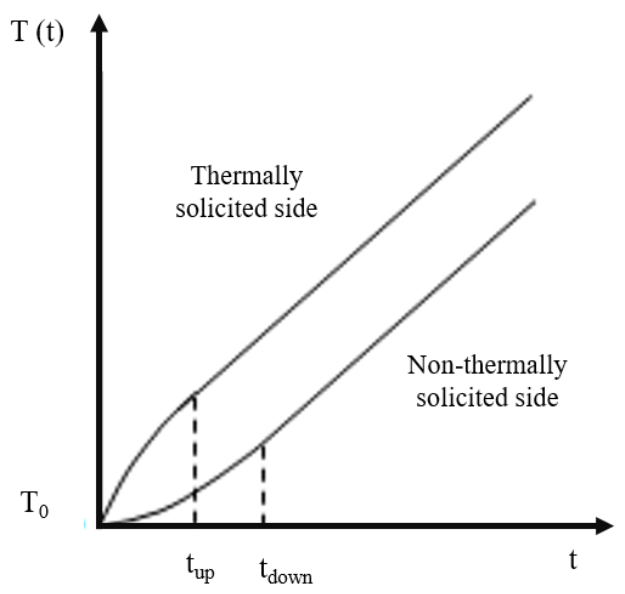

Figure 2: Theoretical temperature profile for the top and bottom surfaces of a sample [23]

After times $t_{\text {up }}$ and $t_{\text {down }}$, which depend on the characteristic diffusion time over the sample thickness, the exponential term is simplified and thus temperature profiles at $x=0$ and $x=e$ become linear, in agreement with the analytical solution of the heat transfer equation as follows [25]:

$T\left(x=e, t>t_{u p}\right)=T_{0}+\frac{\phi_{0} t}{\rho c_{p} e}+\frac{\phi_{0} e}{3 k}$

$T\left(x=0, t>t_{\text {down }}\right)=T_{0}+\frac{\phi_{0} t}{\rho c_{p} e}-\frac{\phi_{0} e}{6 k}$

Equations (6) and (7) allow us to establish the following expressions:

$\rho c_{p}=\frac{\phi_{0}}{s e} \quad ; k=\frac{\phi_{0} e}{2 \delta T}$

where $s$ is the slope of the temperature curve for $t>t_{\text {down }}$, and $\delta T$ is the temperature difference between the top and the bottom faces of the sample for $t>t_{\text {down }}$. In the proposed method, we wait for the difference between both slopes to be stabilized. The estimation of the parameters $k$ and $c_{p}$ is obtained using the least squares method between the expressions of equation (8) and the experimental data.

The specific heat capacity $c_{p}$ represents the quantity of heat a material is able to absorb with regard to its mass. The thermal conductivity $k$ of a material quantifies its ability to conduct heat, while thermal diffusivity characterizes the rate at which heat is transferred through a given material. Finally, thermal effusivity $E$, also referred to as thermal admittance, represents the rate at which heat is absorbed by a material. The higher the effusivity, the higher the material will absorb energy without notably increasing its temperature. These four physical quantities allow the characterization of thermal inertia, that is to say the ability for a material of storing heat and returning it through time. 
The experiment is conducted five times for each sample to ensure that results are reproducible. To ensure that data from different tests is comparable despite slight variations in initial temperature and heat flux, a reduced temperature is used, noted $T^{*}$ (in $\mathrm{K} \cdot \mathrm{m}^{2} . \mathrm{W}^{-1}$ ), defined as:

$T^{*}(x, t)=\frac{T(x, t)-T_{0}}{\phi_{0}}$

For each test and each method, the temperature and fluxmeter sensor positions were deliberately changed between two consecutive trials in order to ensure that this position did not influence the results, and different trials were then combined using $T^{*}$. The thermal properties estimated with this method are then compared with those obtained with the hot-disk and the hot-plate methods with the same samples.

\subsection{Validation methods procedures}

The Hot Disk method is a transient thermo-physical technique allowing the determination the thermal conductivity, diffusivity and heat capacity of samples. The thermal solicitation is ensured using a Hot Disk sensor, acting as both a heat source and a temperature sensor (here, of radius $3.189 \mathrm{~mm}$ ), placed in between two samples to test [13]. The solicitation time is short (about ten seconds) so that the edges of the sample do not influence the diffusion of heat process. The heat flux delivered by the sensor, of the order of a hundred of $\mathrm{mW}$, is chosen so that the increase of the sample's temperature is included between $1^{\circ}$ and $3^{\circ} \mathrm{C}$. The variation of the sensor's electric resistance resulting from the increase of the material's temperature during the test is recorded, allowing us to deduce the values of $k, a$ and $c_{p}$ straightforwardly, following the method described by Gustafsson (1991) [13].

The second validation method used is the hot plate method, which is a transient technique solely allowing the measurement of the thermal effusivity of a material. A heating element as well as a thermo-flowmeter are sandwiched between a semi-infinite sample of material and an insulating material which effusivity is known. By applying a pulse of constant flux, the resolution of the heat equation on the sample - heating element interface leads to the Laplace transform of the temperature [24]. In order to obtain the theoretical evolution of the temperature within the system, the corresponding expression is then numerically inverted using the Stehfest method [26]. The conductance of the sample - heating element set is firstly calculated by using a symmetrical hot plate device with an insulating material of known effusivity. Contact resistances on each side of the heating element and the effusivity of the studied sample are then determined more precisely using the least squares method.

\subsection{Case study materials}

Six materials commonly used in road construction are characterized: fine-aggregate asphalt (FAA), granite, mortar, stabilized sand, asphalt concrete and Portland cement concrete (PCC). A photograph of each sample is shown in Figure 3.

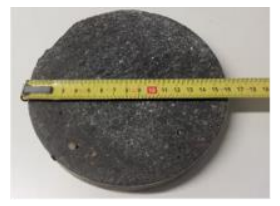

FAA

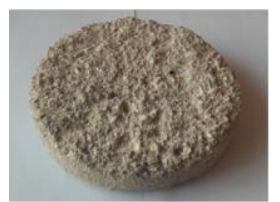

Stabilized sand

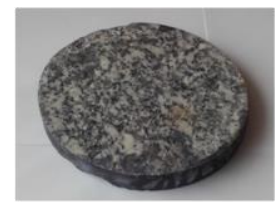

Granite

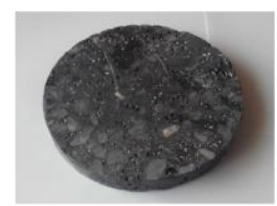

Asphalt concrete

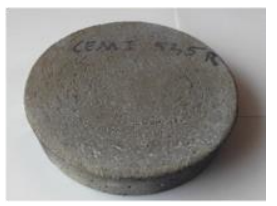

Mortar

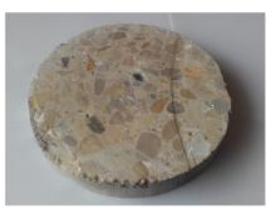

Concrete

Figure 3: Urban material samples 
Each sample was manufactured following the quality control procedure by the City of Paris public space laboratory. Mortar and stabilized sand were directly prepared in a $2 \mathrm{~cm}$-deep cylindrical mould, while FAA, asphalt concrete and PCC were prepared in a cylindrical test tube, and then sawed to the smallest technically feasible thickness, that is $2 \mathrm{~cm}$ slices. Finally, granite was directly core-sampled from a larger sidewalk slab and then sawed. The formulation of the samples as well as the typical size of their aggregates are listed in Table 1.

Table 1: Formulation of the samples and characteristic size of their aggregates

\begin{tabular}{|c|c|c|c|}
\hline \multirow{2}{*}{ Material } & \multirow{2}{*}{ Volumic formulation } & \multicolumn{2}{|c|}{ Aggregates typical diameter } \\
\hline & & Minimal size & Maximal size \\
\hline \multirow{3}{*}{ FAA } & Bitumen $(30 \%)$ & \multicolumn{2}{|c|}{-} \\
\hline & Sand $(40 \%)$ & \multicolumn{2}{|c|}{$<4 \mathrm{~mm}$} \\
\hline & Small Gravel $(30 \%)$ & $2 \mathrm{~mm}$ & $4 \mathrm{~mm}$ \\
\hline Granite & Core-sampled. & - & - \\
\hline \multirow{2}{*}{ Mortar } & \multirow{2}{*}{$\begin{array}{l}\text { Portland Cement }(25 \%) \\
\text { Fine sand }(75 \%)\end{array}$} & \multicolumn{2}{|c|}{-} \\
\hline & & \multicolumn{2}{|c|}{$<2 \mathrm{~mm}$} \\
\hline \multirow{4}{*}{ Stabilized sand } & \multirow{4}{*}{$\begin{array}{l}\text { Portland Cement }(25 \%) \\
\text { Fine sand }(30 \%) \\
\text { Coarse sand }(25 \%) \\
\text { Gravel }(20 \%)\end{array}$} & \multicolumn{2}{|c|}{-} \\
\hline & & \multicolumn{2}{|c|}{$<2 \mathrm{~mm}$} \\
\hline & & \multicolumn{2}{|c|}{$<5 \mathrm{~mm}$} \\
\hline & & $2 \mathrm{~mm}$ & $6 \mathrm{~mm}$ \\
\hline \multirow{3}{*}{ Asphalt concrete } & \multirow{3}{*}{$\begin{array}{l}\text { Bitumen }(30 \%) \\
\text { Fine sand }(20 \%) \\
\text { Coarse gravel }(50 \%) \\
\end{array}$} & \multicolumn{2}{|c|}{-} \\
\hline & & \multicolumn{2}{|c|}{$<2 \mathrm{~mm}$} \\
\hline & & $6 \mathrm{~mm}$ & $10 \mathrm{~mm}$ \\
\hline \multirow{3}{*}{ PCC } & \multirow{3}{*}{$\begin{array}{l}\text { Portland Cement }(25 \%) \\
\text { Sand }(35 \%) \\
\text { Coarse gravel }(40 \%)\end{array}$} & \multicolumn{2}{|c|}{-} \\
\hline & & \multicolumn{2}{|c|}{$<4 \mathrm{~mm}$} \\
\hline & & $4 \mathrm{~mm}$ & $20 \mathrm{~mm}$ \\
\hline
\end{tabular}

From the formulations listed in Table 1, qualitative information on the homogenous/heterogeneous nature of the samples can be obtained. This strongly depends on the scale of analysis, which depends on the size of the instrument. In brief, a material is considered to be heterogeneous if its characteristic aggregates or minerals are similar or larger than the instrument's measurement area, homogeneous otherwise.

Thus, for the $1 \mathrm{~cm}^{2}$ sensors used here, granite and mortar can be considered as homogeneous, since the characteristic size of their constituents, resp. their minerals and sand particles, is at least an order of magnitude smaller than the sensor. FAA, which incorporates a mix of small aggregates (sand and gravel) and bituminous binder, as well as stabilized sand can be considered mildly heterogeneous due to the significant presence of coarse sand and small gravel. Finally, asphalt concrete and PCC are both strongly heterogeneous since they include a significant portion of centimetric aggregates.

The manufacturing procedures employed to produce the samples imposed the sawing of asphalt concrete, FAA, PCC and granite, leaving them with and a smooth finish. The surface roughness of these is thus low, i.e. less than $0.1 \mathrm{~mm}$. This holds true for mortar, which is smooth as well. On the contrary, stabilized sand is a porous material with a very rough finish, with a roughness estimated to be in the order of $3 \mathrm{~mm}$.

For the radiative characterization, cylindrical samples of $16 \mathrm{~cm}$ in diameter and $2 \mathrm{~cm}$ thick are considered in this study (see Figure 3), i.e. larger than the characteristic size of the heterogeneities. For the two validation methods (hot-disk and hot-plate), smaller samples were used $(4.5 \mathrm{~cm}$ in diameter and $2 \mathrm{~cm}$ thick) to match the size of the hot-plate heating element. The density of the samples was measured at 
ambient temperature and are listed in Table 2. Uncertainties given in this Table are the standard deviation of the measurements.

Table 2: Sample densities (at $20^{\circ} \mathrm{C}$ )

\begin{tabular}{|c|c|}
\hline Material & Density $\left(\mathrm{kg} \cdot \mathrm{m}^{-3}\right)$ \\
\hline FAA & $2325 \pm 34$ \\
\hline Granite & $2608 \pm 18$ \\
\hline Mortar & $2157 \pm 14$ \\
\hline Stabilized sand & $2090 \pm 42$ \\
\hline Asphalt concrete & $2360 \pm 34$ \\
\hline PCC & $2301 \pm 50$ \\
\hline
\end{tabular}

Thermal properties and density of various types of asphalts, concretes, mortars and granites found in the literature are listed in Table 3. As seen, these values vary noticeably, as the properties strongly depend on the composition of the sample and on its manufacturing procedure. They should therefore be used for comparison carefully since a vast diversity of civil engineering materials exist. No values were found for the stabilized sand.

Table 3: Literature values for the thermal properties of various types of asphalt, concrete, mortar and granite. $k:$ thermal conductivity $\left(\mathrm{W} \cdot \mathrm{m}^{-1} \cdot \mathrm{K}^{-1}\right)$, a: thermal diffusivity $\left(\mathrm{mm}^{2} \cdot \mathrm{s}^{-1}\right), c_{p}$ : specific heat capacity $\left(\mathrm{J} \cdot \mathrm{kg}^{-1} \cdot \mathrm{K}^{-1}\right), \varrho:$ density $\left(\mathrm{kg} \cdot \mathrm{m}^{-3}\right),-:$ not provided.

\begin{tabular}{|c|c|c|c|c|c|c|}
\hline Material & Reference & Specifications & $k$ & $\bar{a}$ & $c_{p}$ & $\varrho$ \\
\hline \multirow{6}{*}{ Asphalt } & "Luca (2005) [27] & Hot mixed asphalt & $\overline{~ 1.45-1.81}$ & $0.44-0.64$ & $\begin{array}{l}1120-1370 \\
\end{array}$ & $22297-2450$ \\
\hline & Li (2015) [28] & Dense-graded asphalt & 1.73 & 0.85 & 852 & 2400 \\
\hline & $\begin{array}{l}\text { Takebayashi (2012) } \\
{[29]}\end{array}$ & Asphalt & 0.74 & - & 2100 & - \\
\hline & $\begin{array}{l}\text { Kavianipour (1977) } \\
{[30]}\end{array}$ & Asphaltic pavement & $2.28-2.88$ & $1.15-1.44$ & \multicolumn{2}{|c|}{$\varrho \cdot c_{p}=1.97-2.00 \mathrm{MJ} \cdot \mathrm{m}^{-3} \cdot \mathrm{K}^{-1}$} \\
\hline & Highter (1984) [31] & Asphaltic concrete & $0.65-2.32$ & $0.6-1.0$ & $800-1600$ & - \\
\hline & Carlson (2010) [32] & Hot mix asphalt & 0.90 & - & - & 2281 \\
\hline \multirow{6}{*}{ Concrete } & $\begin{array}{l}\text { Howlader (2012) } \\
{[33]}\end{array}$ & $\begin{array}{l}\text { Coarse aggregates } \\
\text { PCC }\end{array}$ & $1.41-2.35$ & $0.57-1.01$ & $1018-1260$ & $1920-2340$ \\
\hline & Li (2015) [28] & $\begin{array}{l}\text { Dense-graded } \\
\text { concrete }\end{array}$ & 1.83 & 0.81 & 1001 & 2257 \\
\hline & Carlson (2010) [32] & PCC & 1.72 & - & - & 2857 \\
\hline & Khan (2002) [34] & Different concretes & $1.60-2.77$ & - & - & - \\
\hline & Kodur (2003) [35] & Aggregate concretes & $1.97-1.98$ & $0.81-1.10$ & \multicolumn{2}{|c|}{ e. $c_{p}=1.8-2.45 \mathrm{MJ} \cdot \mathrm{m}^{-3} \cdot \mathrm{K}^{-1}$} \\
\hline & Lee (2000) [36] & Concrete block & - & - & 880 & - \\
\hline \multirow{3}{*}{ Mortar } & Khan (2002) [34] & Mortar & $1.37-1.90$ & $\begin{array}{l} \\
\end{array}$ & $\begin{array}{c}- \\
\end{array}$ & $\begin{array}{l} \\
\end{array}$ \\
\hline & Bentz (2011) [37] & Silica sand mortars & $1.7-3.2$ & - & $830-1025$ & $2080-2380$ \\
\hline & $\begin{array}{l}\text { Demirboğa (2003) } \\
{[38]}\end{array}$ & $\begin{array}{l}\text { Portland Cement paste } \\
\text { with silica sand }\end{array}$ & $0.72-1.19$ & - & - & $1790-2106$ \\
\hline \multirow{4}{*}{ Granite } & Cho (2009) [39] & Granite & $2.12-3.12$ & $\begin{array}{l} \\
\end{array}$ & $\begin{array}{l}- \\
\end{array}$ & $2610-2690$ \\
\hline & Heuze (1983) [40] & Several granites & $2.5-3.3$ & $1.1-1.8$ & $750-950$ & 2600 \\
\hline & Petrov (2005) [41] & Krasnoyarsk granites & $3.1-3.4$ & $1.46-1.57$ & $800-840$ & $2610-2750$ \\
\hline & Dwivedi (2008) [42] & Several granites & - & $1.26-1.51$ & $801-836$ & $2590-2600$ \\
\hline
\end{tabular}




\section{Experimental results}

The proposed radiation-based method is applied for each sample, as well as the hot-disk and hot-plate methods. The results obtained from the radiative method are then compared to those from the other two characterization techniques for homogeneous and smooth materials. An example of the temperature variation of the top and bottom faces of the granite sample is provided on Figure 4. From those results, the reduced temperature $T^{*}$ is calculated following equation (9). Several trials are combined to improve the representativeness of the measurement noise. Then, the slope $s$ and difference between top and bottom averaged reduced temperatures $\delta T$ are estimated using the least squares method. Specific heat capacity and thermal conductivity are deduced from equations (8) divided by $\phi_{0}$. Knowing $k, c_{p}$ and $\varrho$, thermal diffusivity $a$ is calculated using relation $a=k / \varrho . c_{p}$ while thermal effusivity $E$ is obtained using relationship $E=\sqrt{ }$ k.e.c.c.

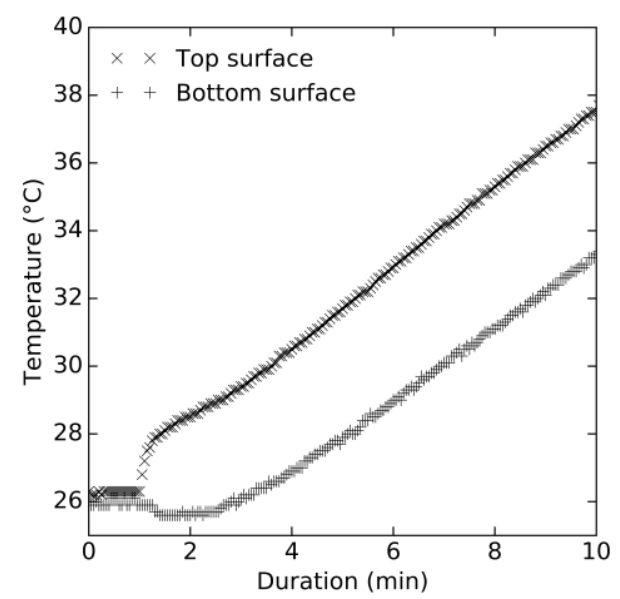

Figure 4: Example of experimental temperature variation of top and bottom surfaces for the granite sample

\subsection{Comparison of the methods}

For the radiative method, the estimated parameter uncertainties provided hereafter are obtained by propagating the measurement uncertainties into relation (6). Diffusivity and effusivity are then calculated from $k, \mathrm{c}_{p}$ and $\varrho$ and the uncertainties are propagated likewise. For the hot-disk method, the parameter uncertainties are obtained using the standard deviation between each trial. Finally, for the hot-plate device, the uncertainties were obtained based on the probability distribution of the estimated effusivity using a 90\% confidence interval in the numerical model [26].

\subsection{Validation: smooth and homogenous materials}

Table 4 presents the results obtained for smooth and homogeneous materials, i.e. the FAA, mortar and granite samples and are also illustrated on Figure 5.

As can be seen, results are in a good agreement for all three characterization methods, with slightly greater uncertainties for diffusivity and specific heat than for conductivity. The greatest difference is observed for the thermal conductivity of FAA with both methods. This might be caused by the mildly heterogeneity of the FAA, causing this slight discrepancy observed here unlike other samples.

In addition, for each parameter, results obtained in this paper seem to compare favorably with properties found in the literature given the wide range of existing construction materials (see Table 3). FAA matches literature values of an asphaltic concrete/pavement [30-31]. Granite is in very good agreement with most references [39-40-42] as is the mortar sample which matches literature properties of a silica sand mortar 
[37]. These observations confirm that the proposed method is able to measure the properties of interest for smooth-surfaced and homogeneous materials.

Table 4: Validation results obtained for homogenous and smooth materials

\begin{tabular}{|c|c|c|c|c|c|c|c|c|c|}
\hline & \multicolumn{2}{|c|}{$k\left(\mathrm{~W} \cdot \mathrm{m}^{-1} \cdot \mathrm{K}^{-1}\right)$} & \multicolumn{2}{c|}{$a\left(\mathrm{~mm}^{2} \cdot \mathrm{s}^{-1}\right)$} & \multicolumn{2}{c|}{$c_{p}\left(\mathrm{~J} \cdot \mathrm{kg}^{-1} \cdot \mathrm{K}^{-1}\right)$} & \multicolumn{3}{c|}{$E\left(\mathrm{~J} \cdot \mathrm{m}^{-2} \cdot \mathrm{K}^{-1} \cdot \mathrm{s}^{-1 / 2}\right)$} \\
\hline & Radiation & $\begin{array}{c}\text { Hot- } \\
\text { disk }\end{array}$ & Radiation & $\begin{array}{c}\text { Hot- } \\
\text { disk }\end{array}$ & Radiation & $\begin{array}{c}\text { Hot- } \\
\text { disk }\end{array}$ & Radiation & $\begin{array}{c}\text { Hot- } \\
\text { disk }\end{array}$ & $\begin{array}{c}\text { Hot- } \\
\text { plate }\end{array}$ \\
\hline \multirow{2}{*}{ FAA } & 2.01 & 2.42 & 0.96 & 1.23 & 900 & 856 & 2051 & 2192 & 2130 \\
& \pm 0.05 & \pm 0.09 & \pm 0.07 & \pm 0.15 & \pm 56 & \pm 110 & \pm 69.7 & \pm 147 & \pm 70.3 \\
\hline \multirow{2}{*}{ Granite } & 2.31 & 2.60 & 1.17 & 1.34 & 759 & 750 & 2138 & 2256 & 2419 \\
& \pm 0.15 & \pm 0.13 & \pm 0.12 & \pm 0.13 & \pm 63 & \pm 62 & \pm 113 & \pm 108 & \pm 94.3 \\
\hline \multirow{2}{*}{ Mortar } & 2.90 & 2.91 & 1.42 & 1.74 & 946 & 787 & 2431 & 222 & 2196 \\
& \pm 0.20 & \pm 0.04 & \pm 0.16 & \pm 0.25 & \pm 79 & \pm 120 & \pm 129 & \pm 169 & \pm 108 \\
\hline
\end{tabular}
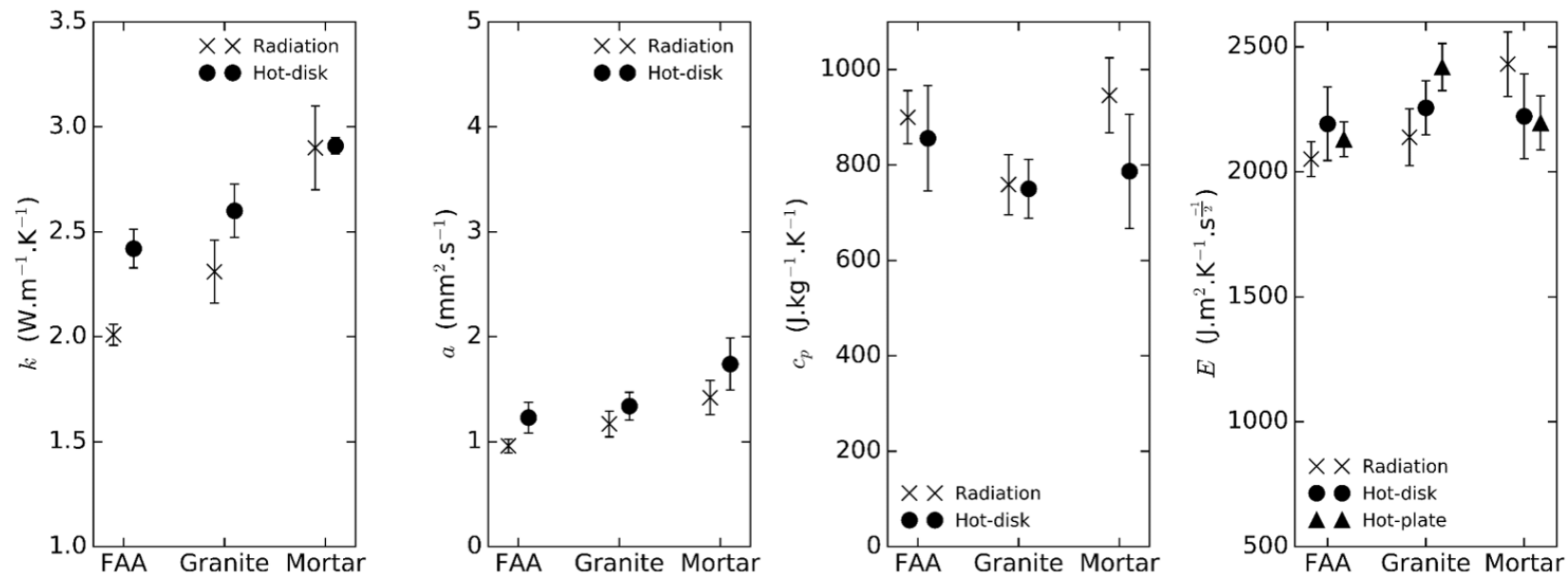

Figure 5: Comparison of the results for homogeneous/smooth samples (fine-aggregate asphalt (FAA), granite and mortar) for all three methods.

\subsection{Heterogeneous and rough materials}

Table 5 summarizes results obtained for the three other case study materials, namely the stabilized sand, which surface is rough, as well as for the asphalt concrete and the concrete sample, highly heterogeneous and plotted in Figure 6. Unlike for homogeneous samples, good agreement is found between the hotdisk and the radiation method for thermal conductivity only.

Table 5: Results obtained for heterogeneous and/or rough materials

\begin{tabular}{|c|c|c|c|c|c|c|c|c|c|}
\hline & \multicolumn{1}{|c|}{$k\left(\mathrm{~W} \cdot \mathrm{m}^{-1} \cdot \mathrm{K}^{-1}\right)$} & \multicolumn{2}{|c|}{$a\left(\mathrm{~mm}^{2} \cdot \mathrm{s}^{-1}\right)$} & \multicolumn{2}{c|}{$c_{p}\left(\mathrm{~J} \cdot \mathrm{kg}^{-1} \cdot \mathrm{K}^{-1}\right)$} & \multicolumn{2}{c|}{$E\left(\mathrm{~J}^{-2} \cdot \mathrm{K}^{-1} \cdot \mathrm{s}^{-1 / 2}\right)$} \\
\hline \hline Radiation & $\begin{array}{c}\text { Hot- } \\
\text { disk }\end{array}$ & Radiation & $\begin{array}{c}\text { Hot- } \\
\text { disk }\end{array}$ & Radiation & $\begin{array}{c}\text { Hot- } \\
\text { disk }\end{array}$ & Radiation & $\begin{array}{c}\text { Hot- } \\
\text { disk }\end{array}$ & $\begin{array}{c}\text { Hot- } \\
\text { plate }\end{array}$ \\
\hline Stabilized & 1.23 & 1.25 & 0.74 & 2.65 & 722 & 369 & 1351 & 982 & 1775 \\
Sand & \pm 0.03 & \pm 0.06 & \pm 0.06 & \pm 2.20 & \pm 21.7 & \pm 259 & \pm 51.3 & \pm 346 & \pm 28.4 \\
\hline Asphalt & 1.63 & 1.87 & 0.86 & 2.61 & 806 & 334 & 1759 & 1214 & 1876 \\
concrete & \pm 0.03 & \pm 0.10 & \pm 0.13 & \pm 1.00 & \pm 118 & \pm 104 & \pm 137 & \pm 192 & \pm 101 \\
\hline PCC & 1.95 & 2.10 & 1.10 & 1.54 & 777 & 140 & 1872 & 823 & 1927 \\
& \pm 0.05 & \pm 0.03 & \pm 0.04 & \pm 0.27 & \pm 10.1 & \pm 51.0 & \pm 33.7 & \pm 150.6 & \pm 67.4 \\
\hline
\end{tabular}



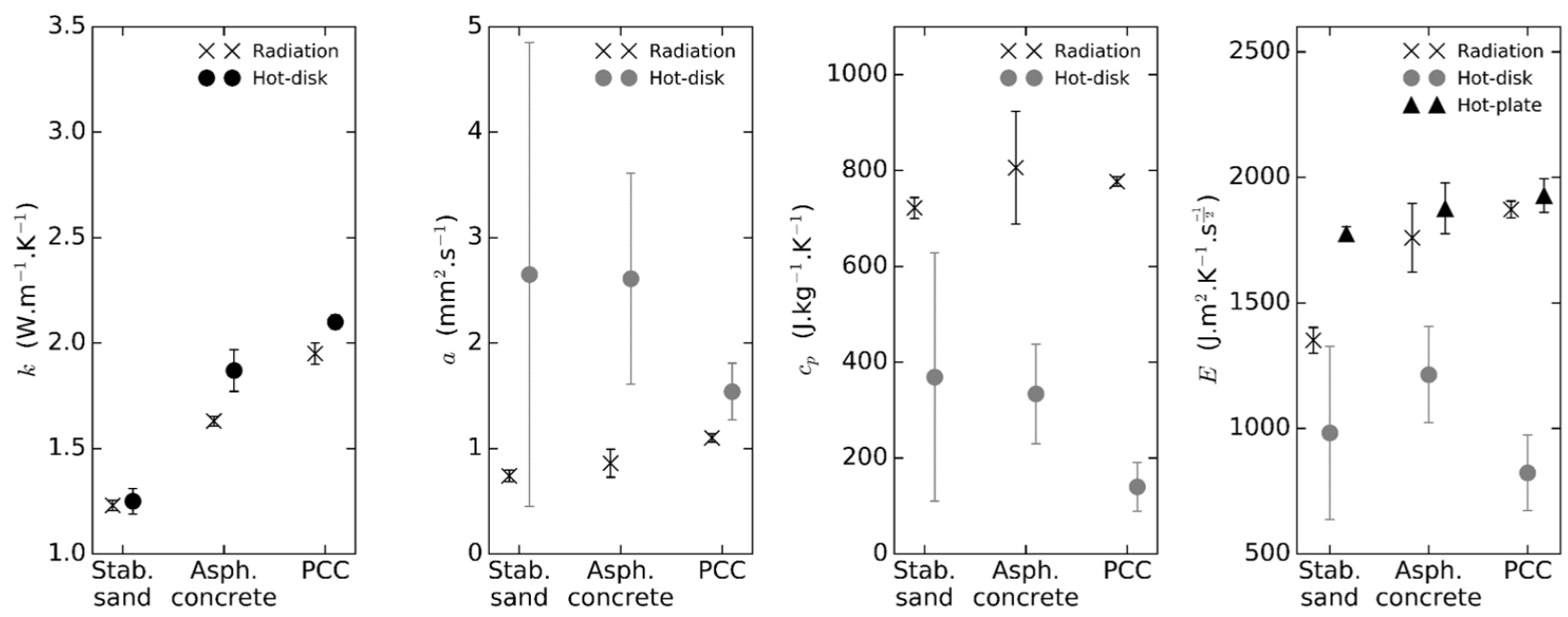

Figure 6: Comparison of the results for heterogeneous/rough samples (stabilized sand (Stab. sand), asphalt concrete (Asph. concrete) and PCC for all three methods.

With the hot-disk method, since thermal conductivity is determined at long time periods [14], it is reassuring to note small variability even with heterogeneous materials, since contact quality mostly influences the reproducibility of the transient portion of the temperature increase, which is mostly sensitive to diffusivity [43].

However, for this reason, the diffusivity and the specific heat results obtained with the hot-disk are highly dispersed, as can be clearly seen in Figure 6. This is particularly the case for diffusivity, but holds true for specific heat as well, the values of which are completely unrealistic.

Indeed, the transient part of the temperature increase has a very strong influence on the evaluation of these properties, and is particularly sensitive to the experimental conditions. For the hot-disk method, rough materials cause a poor contact between the heating element and the sample. High thermal contact resistance therefore appears at this interface, explaining the variability between two successive measurements for which the sensor was deliberately displaced. Moreover, for highly heterogeneous materials (large aggregates), different aggregates are tested between trials. This is due to the inadequate size (too small) of the sensor with regard to the aggregates present in these samples and is a root cause of the observed variability.

Observations in Figure 6 thus confirm the strong impact of poor thermal contact between the sample and the hot-disk sensor for rough samples (stabilized sand) and of large heterogeneities, i.e. the large various-sized aggregates incorporated into the asphalt concrete and the concrete. Corresponding results are therefore greyed in Table 5 and Figure 6 to insist on the fact that they are not reliable and shouldn't be taken into consideration.

For such values, a relative error above $15 \%$ is systematically observed. In the worst case (diffusivity of stabilized-sand with the hot-disk method), this error is even up to $83 \%$. Among the greyed values, the variability of the PCC sample with the hot-disk method seems to be lower compared to the other two materials when looking at the absolute error. Nevertheless, compared to the measured value, the relative error remains above $15 \%$. Moreover, values obtained with the hot-disk technique for each material of Figure 6 are very far from the typical ones found in the literature. Thus, either in terms of variability or values themselves, the hot-disk method does not seem suitable for measuring the thermal properties of our heterogeneous samples apart from conductivity, unlike other methods. 
Indeed, effusivity values obtained for the asphalt concrete and PCC samples with the hot-plate and the radiative characterization methods are in good agreement. Values obtained are quite stable (relative error $<15 \%$ ) and consistent with the literature. This confirms that these two methods have appropriately-sized heating elements for these materials, whereas only the conductivity could be reliably assessed using the hot-disk method.

For reliable results (blackened in Table 5), each measured parameter compares well with the literature (see Table 3). The asphalt concrete sample matches the values of a dense-graded asphalt [28]. Our PCC sample agrees very well with values obtained by Howlader [33] and Kodur [35]. No value was found in the literature for stabilized sand.

All else being equal, the radiation technique gives more stable results compared to the hot-disk method for coarse-aggregate samples, meaning that it is likely to better take into account for the heterogeneities of these structures.

\section{Conclusion}

In order to thermally characterize construction materials with rough surfaces and/or including large aggregates (typically centimetric), a thermo-physical characterization method based on a radiative heat source has been proposed and tested with six different construction materials. This approach was compared with the hot-disk and the hot plate methods for homogenous and smooth-surfaced materials.

For the tests run on smooth materials and with small aggregates, our radiation method showed good agreement with the other two characterization techniques. Indeed, for the estimated parameters, each method exhibited very close results with only slight variability between each trial. Also, for rough and heterogeneous materials, the radiation technique was able to provide apparent thermal properties that were highly reproducible between trials, i.e. for the stabilized sand, asphalt concrete and PCC samples.

Generally-speaking, the proposed radiation-based characterization technique provides satisfactory results for construction materials and agrees well with the hot-plate method. Overall, results are consistent with what can be found in the literature given the wide range of construction materials and the uncertainty of the method is globally acceptable given the heterogeneous nature of the samples and the fact that apparent parameters are measured.

To summarize, the proposed radiative characterization method seems well suited for determining the apparent thermal properties of heterogeneous and rough-surfaces construction materials. In this respect, this method can be used to characterize other heterogeneous materials currently being considered for urban heat island mitigation.

\section{Acknowledgements}

The authors acknowledge the technical support of Jérôme Lefebvre from the City of Paris public space laboratory and his expertise.

\section{References}

[1] Shimoda, Y. (2003). Adaptation measures for climate change and the urban heat island in Japan's built environment. Building Research \& Information, 31(3-4), 222-230.

[2] Mallick, R. B., Chen, B. L., \& Bhowmick, S. (2009). Harvesting energy from asphalt pavements and reducing the heat island effect. International Journal of Sustainable Engineering, 2(3), 214-228.

[3] Knowlton, K., Lynn, B., Goldberg, R. A., Rosenzweig, C., Hogrefe, C., Rosenthal, J. K., \& Kinney, P. L. (2007). Projecting heat-related mortality impacts under a changing climate in the New York City region. American Journal of Public Health, 97(11), 2028-2034. 
[4] Gui, J., Phelan, P. E., Kaloush, K. E., \& Golden, J. S. (2007). Impact of pavement thermophysical properties on surface temperatures. Journal of materials in civil engineering, 19(8), 683-690.

[5] ShengYue, W., QiYang, Z., YingNa, D., \& PeiDong, S. (2013). Unidirectional heat-transfer asphalt pavement for mitigating the urban heat island effect. Journal of materials in civil engineering, 26(5), 812-821.

[6] Mohajerani, A., Bakaric, J., \& Jeffrey-Bailey, T. (2017). The urban heat island effect, its causes, and mitigation, with reference to the thermal properties of asphalt concrete. Journal of environmental management, 197, 522-538.

[7] Harlan, S., Chowell, G., Yang, S., Petitti, D., Morales Butler, E., Ruddell, B., \& Ruddell, D. (2014). Heat-related deaths in hot cities: estimates of human tolerance to high temperature thresholds. International journal of environmental research and public bealth, 11(3), 3304-3326.

[8] Prelovsek, P., \& Uran, B. (1984). Generalised hot wire method for thermal conductivity measurements. Journal of Physics E: Scientific Instruments, 17(8), 674.

[9] Andersson, P., \& Bäckström, G. (1976). Thermal conductivity of solids under pressure by the transient hot wire method. Review of Scientific Instruments, 47(2), 205-209.

[10] Jannot, Y., Felix, V., \& Degiovanni, A. (2010). A centered hot plate method for measurement of thermal properties of thin insulating materials. Measurement Science and Technology, 21(3), 035106.

[11] Huang, J. (2006). Sweating guarded hot plate test method. Polymer testing, 25(5), 709-716.

[12] Log, T., \& Gustafsson, S. E. (1995). Transient plane source (TPS) technique for measuring thermal transport properties of building materials. Fire and materials, 19(1), 43-49.

[13] Gustafsson, S. E. (1991). Transient plane source techniques for thermal conductivity and thermal diffusivity measurements of solid materials. Review of scientific instruments, 62(3), 797-804.

[14] Danis, M., Gobbé, C., \& Royer, J. J. (1996). Procédures d'utilisation d'un conductivimètre à barre divisée pour des échantillons grenus: application au cas des granites. International journal of heat and mass transfer, 39(10), 2183-2187.

[15] Bahrani, S. A., Jannot, Y., \& Degiovanni, A. (2014). Extension and optimization of a three-layer method for the estimation of thermal conductivity of super-insulating materials. Journal of Applied Physics, 116(14), 143509.

[16] Gobbé, C., Iserna, S., \& Ladevie, B. (2004). Hot strip method: application to thermal characterisation of orthotropic media. International Journal of Thermal Sciences, 43(10), 951-958.

[17] Olives, R. (2017). Intensification des transferts et efficacité énergétique du stockage thermique. Habilitation à Diriger des Recherches, Université de Perpignan Via Domitia, pp. 42-51. (In french)

[18] Yan, X., Chen, L., You, Q., \& Fu, Q. (2018). Experimental analysis of thermal conductivity of semi-rigid base asphalt pavement. Road Materials and Pavement Design, 1-13.

[19] Krapez, J. C., Spagnolo, L., Frieß, M., Maier, H. P., \& Neuer, G. (2004). Measurement of in-plane diffusivity in nonhomogeneous slabs by applying flash thermography. International journal of thermal sciences, 43(10), 967-977.

[20] Parker, W. J., Jenkins, R. J., Butler, C. P., \& Abbott, G. L. (1961). Flash method of determining thermal diffusivity, heat capacity, and thermal conductivity. Journal of applied physics, 32(9), 1679-1684.

[21] Degiovanni, A., Batsale, J. C., \& Maillet, D. (1996). Mesure de la diffusivité longitudinale de matériaux anisotropes. Revue générale de Thermique, 35(410), 141-147. (In french)

[22] Degiovanni, A. (1987). Correction de longueur d'impulsion pour la mesure de la diffusivité thermique par méthode flash. International journal of heat and mass transfer, 30(10), 2199-2200. 
[23] Crabol, J. (1989). Transfert de chaleur, Tome 1. Ed. Masson. pp. 88 (In french)

[24] Jannot, Y. (2011). Théorie et pratique de la métrologie thermique. LEMTA, pp.97. (In french)

[25] Jannot, Y. (2012). Transferts thermiques. Ecole des Mines Nancy, pp.43. (In french)

[26] Stehfest, H. (1970). Algorithm 368: Numerical inversion of Laplace transforms [D5]. Communications of the ACM, 13(1), 47-49.

[27] Luca, J., \& Mrawira, D. (2005). New measurement of thermal properties of superpave asphalt concrete. Journal of Materials in Civil Engineering, 17(1), 72-79.

[28] Li, H. (2015). A comparison of thermal performance of different pavement materials. In Eco-Efficient Materials for Mitigating Building Cooling Needs (pp. 63-124). Woodhead Publishing.

[29] Takebayashi, H., \& Moriyama, M. (2012). Relationships between the properties of an urban street canyon and its radiant environment: Introduction of appropriate urban heat island mitigation technologies. Solar Energy, 86(9), $2255-2262$.

[30] Kavianipour, A., \& Beck, J. V. (1977). Thermal property estimation utilizing the Laplace transform with application to asphaltic pavement. International Journal of Heat and Mass Transfer, 20(3), 259-267.

[31] Highter, W. (1984). Thermal properties of some asphaltic concrete mixes. In International Air Transportation Conference(p. 1598).

[32] Carlson, J. D., Bhardwaj, R., Phelan, P. E., Kaloush, K. E., \& Golden, J. S. (2010). Determining thermal conductivity of paving materials using cylindrical sample geometry. Journal of materials in civil engineering, 22(2), 186-195.

[33] Howlader, M. K., Rashid, M. H., Mallick, D., \& Haque, T. (2012). Effects of aggregate types on thermal properties of concrete. ARPN Journal of Engineering and applied sciences, 7(7), 900-906.

[34] Khan, M. I. (2002). Factors affecting the thermal properties of concrete and applicability of its prediction models. Building and Environment, 37(6), 607-614.

[35] Kodur, V. K. R., \& Sultan, M. A. (2003). Effect of temperature on thermal properties of high-strength concrete. Journal of materials in civil engineering, 15(2), 101-107.

[36] Lee, T., Hawes, D. W., Banu, D., \& Feldman, D. (2000). Control aspects of latent heat storage and recovery in concrete. Solar energy materials and solar cells, 62(3), 217-237.

[37] Bentz, D. P., Peltz, M. A., Duran-Herrera, A., Valdez, P., \& Juarez, C. A. (2011). Thermal properties of high-volume fly ash mortars and concretes. Journal of Building Physics, 34(3), 263-275.

[38] Demirboğa, R. (2003). Influence of mineral admixtures on thermal conductivity and compressive strength of mortar. Energy and buildings, 35(2), 189-192.

[39] Cho, W. J., Kwon, S., \& Choi, J. W. (2009). The thermal conductivity for granite with various water contents. Engineering geology, 107(3-4), 167-171.

[40] Heuze, F. E. (1983, February). High-temperature mechanical, physical and thermal properties of granitic rocks—a review. In International Journal of Rock Mechanics and Mining Sciences \& Geomechanics Abstracts (Vol. 20, No. 1, pp. 3-10). Pergamon.

[41] Petrov, V. A., Poluektov, V. V., Zharikov, A. V., Nasimov, R. M., Diaur, N. I., Terentiev, V. A., ... \& Lind, E. N. (2005). Microstructure, filtration, elastic and thermal properties of granite rock samples: implications for HLW disposal. Geological Society, London, Special Publications, 240(1), 237-253.

[42] Dwivedi, R. D., Goel, R. K., Prasad, V. V. R., \& Sinha, A. (2008). Thermo-mechanical properties of Indian and other granites. International Journal of Rock mechanics and mining Sciences, 45(3), 303-315.

[43] Krapez, J. C. (2007). Mesure de l'effusivité thermique. Ed. Techniques Ingénieur. (In french) 